\title{
Los contratos normativos y los contratos marco en el derecho privado contemporáneo
}

\author{
Regulatory Contracts and Framework Contracts in Contemporary \\ Private Law \\ Os contratos normativos e os contratos marco no direito privado \\ contemporâneo
}

\section{Marcela Castro de Cifuentes}

FECHA DE RECEPCIÓN: 13 DE JULIO de 2018. FeCHA DE APROBACIÓN: 21 DE SEPTIEMBRE de 2018

DoI: http://dx.doi.org/10.12804/revistas.urosario.edu.co/sociojuridicos/a.6977

Para citar este artículo: Castro de Cifuentes, M. (2019). Los contratos normativos y los contratos marcon en el derecho privado contemporáneo. Estudios Socio-Jurídicos, 21(1), 121-150. Doi: http://dx.doi.org/10.12804/revistas.urosario.edu. co/sociojuridicos/a.6977

\section{RESUMEN}

La libertad de configuración contractual permite a los particulares diseñar los instrumentos jurídicos que regirán su relación de negocios. Las partes bien pueden utilizar los tipos establecidos en el ordenamiento o pueden crear un acuerdo a su medida que refleje la operación específica que se proponen. También, pueden establecer una metodología y unas etapas en la formación del contrato que vayan desde las primeras conversaciones hasta la conclusión y perfeccionamiento del negocio. El "contrato normativo" y el "contrato marco" son instrumentos empleados con frecuencia en la contratación contemporánea. Por su importancia, han sido objeto de estudio en el ámbito del derecho, pero no hay consenso alrededor de su concepto, su naturaleza y sus efectos. El presente documento presenta los elementos fundamentales que nutren los contratos normativos y los contratos marco, analiza sus principales problemáticas y, finalmente, plantea unas preguntas de reflexión al respecto.

Palabras clave: contrato normativo, contrato marco, contrato tipo.

* Abogada de la Universidad de los Andes. Magíster en Derecho Comparado de la Universidad de Illinois. Profesora Titular de la Universidad de los Andes. Docente e investigadora en derecho privado. Correo electrónico: macastro@uniandes.edu.co. ORCID: http://orcid.org/00000002-5853-5257. 


\section{ABSTRACT}

Freedom of contract allow the parties to design the legal instruments that will govern their business relationship. They may employ the usual contractual types provided by law but also can create tailor made solutions for their particular transaction. Parties can also agree on a method and on different stages in the formation of their contract, starting from the initial negotiations until the final execution of the contract. Normative contracts and the framework agreements are used nowadays as means to organize economic transactions. They have been studied by the legal doctrine but there is no consensus around their meaning, legal nature and effects. This paper examines these special agreements and reflects on their advantages and problems.

Keywords: Normative contracts, framework agreements, model contracts.

\section{RESUMO}

A liberdade de configuração contratual permite aos particulares desenhar os instrumentos jurídicos que regerão sua relação negocial. As partes bem podem utilizar os tipos estabelecidos no ordenamento ou podem criar um acordo à sua medida que reflexe a operação específica que se propõem. Também podem estabelecer uma metodologia e umas etapas na formação do contrato, que vão desde as primeiras conversações até a conclusão e aperfeiçoamento do negócio. O "contrato normativo" e o "contrato marco" são instrumentos empregados com frequência na contratação contemporânea. Pela sua importância, têm sido objeto de estudo no âmbito do direito, mas não há consenso ao redor de seu conceito, sua natureza e seus efeitos. O presente documento apresenta os elementos fundamentais que nutrem os contratos normativos e os contratos marco, analisa suas principais problemáticas e finalmente apresenta umas perguntas de reflexão ao respeito.

Palavras-chave: contrato normativo, contrato marco, contrato tipo. 


\section{Presentación}

De conformidad con el añejo principio pacta sunt servanda, ampliamente conocido y aplicado en la esfera del derecho, todo contrato legalmente celebrado es una ley para las partes, es decir, los acuerdos válidos tienen para aquellas la misma fuerza vinculante que la ley. No es extraño, entonces, hablar de la "normatividad de los contratos" pues, a través de ellos, y en ejercicio de la autonomía de la voluntad, los contratantes crean y se autoimponen un cuerpo de reglas que gobernará su relación en particular. Como consecuencia de su fuerza obligatoria, la infracción de tales normas, convencionalmente creadas, dará lugar a los remedios legales de ejecución forzosa y de resolución, en ambos casos con indemnización de perjuicios, como mecanismos de protección del derecho crediticio (Código de Civil, Artículo 1546; Código de Comercio, Artículo 870).

A pesar de la similitud semántica, un fenómeno muy diferente es el que se manifiesta a través de los llamados contratos normativos propiamente dichos. Este es un término acuñado en época más reciente para identificar un mecanismo contractual que se viene utilizando en las relaciones negociales, fruto de la experiencia recogida de las actividades económicas que se desarrollan masivamente en el mercado de bienes y servicios.

Por otro lado, ha surgido con fuerza el contrato marco como una forma particular de celebrar ciertos negocios y que, se verá, ha sido identificado por algunos doctrinantes como sinónimo de contrato normativo.

El estudio de los contratos normativos se inició hace varias décadas, sobre todo en las doctrinas alemana e italiana, y luego llamó la atención de los juristas de otros países. A su turno, los contratos marco nacieron como un dispositivo utilizado en la práctica contractual, sobre todo en los países del common law. Estas modalidades especiales de contratación que surgieron para atender las necesidades de los agentes económicos pueden adoptar diversas formas y manifestaciones, por lo que ha sido particularmente difícil delimitar en forma precisa o unívoca su definición, su alcance y sus implicaciones jurídicas. Precisamente, esta complejidad ha despertado el interés de los juristas al comprobar la creciente utilización de dicho mecanismo en la praxis y ha suscitado importantes debates en la doctrina internacional. 
Con el objeto de contribuir a la discusión académica sobre nuevas formas de contratación, sus manifestaciones en la vida económica y para identificar las problemáticas que ellas suscitan, de cara a los principios tradicionales del derecho contractual de los negocios, en este escrito se abordará, de manera sucinta, el estudio de los contratos normativos y los acuerdos marco. Para ese efecto, el tema se desarrollará en el siguiente orden: su origen (1); el problema terminológico (2); concepto, naturaleza jurídica y efectos (3); la función económica (4); los mecanismos afines (5); y, a título de conclusión, algunas preguntas de reflexión sobre los contratos normativos y los contratos marco (6) 1 .

La metodología que se empleó para la elaboración del texto fue la de rastrear los temas en la doctrina especializada, nacional y comparada, acudiendo a la vez a los principios básicos de la contratación. Se acudió a la jurisprudencia arbitral para ilustrar algunos casos en los que se han examinado las categorías estudiadas, para luego valorar y contrastar diversas posturas con el propósito de precisar los conceptos y de reflexionar sobre la problemática de estas novedosas formas de contratación que desafían las categorías tradicionales del derecho privado.

\section{Origen de los contratos normativos y de los contratos marco}

El siglo XX fue testigo de la masificación de las relaciones económicas y del surgimiento de nuevas formas de contratación como respuesta a las transformaciones ocurridas en el medio social. Aun cuando el capitalismo se caracteriza por una marcada tutela del interés individual, las formas asociativas y las grandes organizaciones han protagonizado la actividad industrial y comercial en las últimas décadas. Así lo expresó el doctrinante alemán Alfred Hueck (1923), pionero en el estudio del tema: la economía moderna gira en torno a las organizaciones y reemplaza al individuo, quien antes ocupaba el rol central (p. 33). 
En ese contexto, Hueck, con su obra Contratos normativos, publicada en 1923, es precursor en el estudio de esta modalidad contractual que floreció en las sociedades con economías masificadas. Para el autor, "(...) siempre que las cláusulas contractuales no estén fijadas en el contrato en el cual deben regir, sino que estén pactadas en un contrato especial, y cuando esas cláusulas contractuales no deban regir únicamente para un solo contrato, sino para una serie de contratos, se está ante la presencia de un contrato normativo"2 (Hueck, 1923, p. 37).

Hueck explica que el contrato normativo no contiene ninguna obligación futura de celebrar ciertos contratos, sino que aquel solo tendrá vigencia en caso de que tales contratos individuales sean concluidos, de manera que se distingue el contrato normativo de los contratos individuales que pueden celebrarse subsecuentemente. Si esto ocurre, estos contratos posteriores habrán perdido independencia y deberán contener una parte sustancial del contenido del contrato normativo que antecede (Hueck, 1923, pp. 38-40). No obstante, debe puntualizarse que las partes conservan su autonomía para decidir si celebran o no en el futuro los contratos individuales. En su obra, el autor señala que estos contratos pueden ser unilaterales o bilaterales; los primeros se asimilan, en realidad, a las condiciones predispuestas, al paso que los segundos se configuran cuando partes con intereses recíprocos pactan los contratos normativos.

De otro lado, destaca que en estos contratos las partes difieren de aquellas que intervienen en los contratos tradicionales: los partícipes son quienes han celebrado el contrato normativo, pero este puede proyectar sus efectos a terceros, personas externas que celebran contratos individuales con quienes han sido partícipes, pero tales terceros no son parte en el contrato normativo.

Lo anterior plantea una problemática muy interesante y actual en la disciplina de los contratos normativos -como lo reconocen los autores contemporáneos- sobre su efecto relativo o extendido a personas que

2 El autor ilustra esta categoría de contratos con aquellos de carácter colectivo que celebraba un gremio de empleadores con un gremio de trabajadores fijando una tarifa que marcaba la pauta en los contratos individuales que se celebrarían ulteriormente. También menciona las convenciones de precio celebradas entre fabricantes para sentar los precios que debían pactarse en los contratos de suministro con los respectivos clientes. Aunque el derecho laboral y el derecho antitrust prohíben estos pactos en la actualidad, los ejemplos son ilustrativos de la función originaria de los contratos normativos. 
acuerdan los contratos individuales pero que no han dado su consentimiento para la conformación del contrato normativo.

Posteriormente, en Italia, Messineo (1948) estudió el contrato normativo y lo distinguió del "contrato en sentido técnico". Este se encuentra definido por el Artículo 1321 del Codice Civile como el acuerdo de dos o más partes para constituir, regular o extinguir una relación jurídica patrimonial, noción que, dicho sea de paso, fue adoptada por el Artículo 864 del Código de Comercio colombiano.

Según el maestro italiano, el contrato normativo tiene por contenido el establecimiento de normas jurídicas con eficacia limitada, en principio, a los sujetos contrayentes, aunque pueden aplicarse, en ciertas hipótesis, a terceros que son destinatarios del mismo, por colocarse en el supuesto de hecho previsto por aquel (Messineo, 1948, pp. 57-58). Así las cosas, el contrato, en sentido estricto, enuncia un resultado concreto y específico para las partes, influye en la relación de manera inmediata y de él nacen derechos y obligaciones al paso que el contrato normativo persigue un resultado abstracto y general, influye de manera mediata en la relación y nunca es idóneo, por sí, para determinar derechos y obligaciones directamente.

Siguiendo la línea argumentativa de Messineo, el contrato normativo no es, en sentido estricto, un contrato. Este último tiene fuerza de ley para las partes, su contenido es concreto y determinado, en tanto que el contrato verdaderamente normativo rationae materiae dispone de intereses en abstracto y, de modo general, en situaciones susceptibles de repetirse; es un fenómeno de autodisciplina o autoimposición de normas admisibles en cuanto no estén en oposición con normas imperativas (Messineo, 1948, pp. 59-62). Por esa razón, el autor sostiene que al llamado contrato normativo le conviene mejor la calificación de "acuerdo", formulación que plantea una dificultad no solo en cuanto a la denominación de este mecanismo contractual sino sobre su propia naturaleza jurídica, asunto que retomaremos posteriormente.

Se observa cómo, desde las primeras décadas del siglo XX, el contrato normativo interesó a los doctrinantes por sus peculiares características y puede afirmarse que a pesar de su importancia jurídica y práctica aún no ha encontrado un ambiente propicio para que su tipificación legal se generalice en el conjunto de los sistemas jurídicos de corte romanogermánico. 
A diferencia de los contratos normativos, el origen del contrato marco no es fácil de rastrear en los estudios dogmáticos. Sin embargo, es evidente que este dispositivo surgió en el siglo Xx como una práctica dirigida a facilitar la negociación de ciertos acuerdos en los que, de entrada, es posible la fijación de ciertos parámetros, pero su ejecución requiere de la determinación de necesidades específicas de las partes que se van concretando de forma gradual en el curso de una relación jurídica estable que se plantea como de mediana o larga duración.

\section{El problema terminológico}

En primer lugar, debe advertirse que en esta materia existe gran diversidad en las acepciones atribuidas por la doctrina a la expresión "contrato normativo" y ello contribuye a la confusión que existe alrededor de esta clase de acuerdos. En general, puede afirmarse que, en virtud de ellos, dos o más partes convienen adoptar unas reglas que deberán observar en futuros contratos que entre ellas mismas o con terceros podrán o no celebrarse. En el primer caso se denominan contratos normativos internos y, en el segundo, externos (Balestieri, 2012, p. 1423).

En ese orden de ideas, Díez-Picazo (1996) afirma que el contrato normativo es un contrato que tiene por objeto establecer la disciplina de un contrato eventual y futuro, sin que produzca ninguna obligación de concluir el contrato futuro puesto que en el mismo se fija únicamente el contenido de esos futuros contratos que las partes no están obligadas a celebrar (Díez-Picazo, 1996, p. 363).

Para Soro Russell (2014), "[e]l término contrato normativo designa una categoría jurídica que aglutina a todos aquellos contratos que, en lugar de disciplinar un simple intercambio de prestaciones, regulan una compleja, estrecha y duradera relación de cooperación entre sujetos con intereses convergentes y su desarrollo mediante la conclusión de una futura y eventual multiplicidad de actos jurídicos de diversa naturaleza, tanto entre ellos mismos como con terceros" (pp. 282-283).

Por su parte, D'Arcangelo (2008) señala que el contrato normativo está destinado a fijar, en todo o en parte, el contenido de una serie de contratos para ser concluidos sucesivamente sin que las partes se obliguen 
por ello a estipular estos últimos (p. 62). El autor se refiere también a los contratos normativos unilaterales y bilaterales; en los primeros, el esquema acordado se insertará en un acuerdo futuro que se celebrará entre un tercero y una de las partes que ha concluido el contrato normativo. Los bilaterales se refieren a estipulaciones que serán incorporadas a un contrato posterior entre las mismas partes que convinieron el contrato normativo (D'Arcangelo, 2008, p. 65).

En Colombia, como ocurre en otros sistemas jurídicos, esta categoría no ha sido reconocida expresamente por la ley. Según Hinestrosa (2015), por medio de lo que indistintamente denomina "acuerdo o contrato normativo", las partes determinan el contenido de los contratos que una de ellas llegue a celebrar con terceros, como ocurre en la distribución de bienes, en la que el distribuidor utiliza un modelo para los contratos que celebre con sus clientes. Excluye de su definición que los futuros contratos sean celebrados entre las mismas partes. En cambio, sí destaca el elemento ya mencionado: a diferencia del contrato preliminar, ninguna de las partes del contrato normativo está obligada a celebrar los contratos futuros (p. 879).

Por su parte, Rengifo (2015), al estudiar los contratos normativos - que identifica con las nociones de contrato marco y contrato tipo-, indica que son reglamentos contractuales en cuya elaboración han participado las personas que habrán de someterse a ellos en caso de celebración de futuros contratos, que denomina "contratos de fondo". Como mencionaremos más adelante, a nuestro juicio, deben distinguirse las tres categorías arriba mencionadas. En otras palabras, el contrato normativo no es sinónimo ni comprende como subcategorías las de contrato marco y contrato tipo. De hecho, al explicar las clases de contratos normativos, el autor señala que los contratos marco están destinados a regular una relación jurídica determinada y concreta: fijar por anticipado el contenido de un contrato si las partes deciden celebrarlo. En cambio, los contratos tipo están destinados a regular un número indefinido de eventuales contratos entre las partes o entre las partes y terceros, como es el caso de las convenciones colectivas de trabajo (Rengifo, 2015, p. 381). 
La jurisprudencia arbitral nacional ha asimilado el contrato normativo y el contrato marco, y al respecto ha señalado ${ }^{3}$ :

Dicho acuerdo fija unos términos generales y abstractos que vinculan a las partes, pero requieren, para la activación de sus cláusulas, de los contratos de aplicación o de ejecución que serán acuerdos ulteriores y detallados mediante los cuales se desarrolla el contrato marco. Si ya se encuentran definidas las estipulaciones generales, las partes llegan en cada oportunidad a compromisos específicos sobre bienes, servicios, calidades, precios, cantidades, fechas de entrega, etc., mediante los cuales ejecutan las prestaciones en concreto, según las necesidades que surgen en el desenvolvimiento de la relación (Cámara de Comercio de Bogotá, 2015).

En otro lado, el Tribunal afirmó que el "Contrato Marco" no corresponde, estrictamente, a un tipo o clase de contrato en particular y desde ese punto de vista no se distingue de otros de diversa naturaleza o tipología, sino que corresponde a una modalidad de contratación, a un particular diseño de la convención de las partes conforme al cual estas acuerdan las condiciones generales que gobernarán sus relaciones jurídicas futuras, en el curso de la vigencia del contrato (Cámara de Comercio de Bogotá, 2016).

Algunos autores extranjeros proveen definiciones abiertamente distintas, como es el caso del argentino Lorenzetti (2004) quien, sobre el contrato normativo, afirma que es un contrato preparatorio con una reglamentación impuesta por legislación de orden público, que establece contratos tipo, por ejemplo el contrato de seguro, la medicina prepaga, el contrato bancario, donde rige el modelo predeterminado por el organismo correspondiente y resulta por ende, obligatorio. No obstante, estima que la convención colectiva de trabajo es una forma de contrato normativo. Añade que el contrato marco es, por lo general, un vínculo de larga duración que establece las reglas generales dentro de las que se encuadrarán las conductas de las partes y que esto se hace de común acuerdo entre ellas (Lorenzetti, 2004, pp. 307-308).

3 Hasta la fecha de redacción de este documento la autora no conoce fallos de casación sobre el particular. 
Gregorini (2009) es de la misma opinión y define el contrato normativo como aquel "cuyo marco regulatorio está impuesto por una legislación de orden público insusceptible de apartamiento, pudiendo revestir la forma de un contrato tipo" (p. 383). Señala, además, que todos los contratos preparatorios contemplan una eventual contratación futura y también distingue los contratos normativos de los contratos marco y de los contratos reglamentarios (o contratos tipo). Los primeros - marco- prevén la conclusión eventual y relativamente inmediata de determinados contratos de aplicación o de ejecución, mientras que los segundos -tipo- se elaboran mediante formularios o modelos estándar y proveen la uniformidad sobre la que se celebrarán los futuros contratos, uniformidad que puede ser establecida en forma unilateral o bilateral. Si es unilateral, hay un riesgo de imposición abusiva, sobre todo cuando la aceptación de la parte no predisponente se hace bajo la forma de adhesión.

En cuanto a los contratos marco, debe destacarse su consagración positiva en la reforma legislativa al Código Civil aprobada en Francia y que rige a partir de 2016. El Artículo 1109 del Code consagra una definición amplia de contrato: es un acuerdo de voluntades, entre dos o varias personas, destinado a crear efectos de derecho. Y el Artículo 1109 dispone:

Le contrat-cadre est un accord par lequel les parties conviennent des caractéristiques essentielles de leurs relations contractuelles futures. Des contrats d'application en précisent les modalités d'éxécution ${ }^{4}$.

Nótese que la figura regulada se integró al capítulo correspondiente a la clasificación de los contratos, de manera que el contrato marco se considera un contrato más, un contrato en sí mismo y nada se menciona sobre su carácter preparatorio en la reglamentación sobre la formación del contrato. De otra parte, no se acogió legislativamente la categoría de contrato normativo, lo que parece indicar que la ley francesa no asimila este último con el contrato marco 5 .

4 "El contrato marco es un acuerdo por el que las partes convienen características esenciales de sus relaciones contractuales futuras. Los preceptos de ejecución del contrato marco se precisarán por medio de contratos de aplicación."

5 Por otro lado, el Artículo 1164 permite que en los contratos marco se convenga que el precio de la prestación sea fijado de manera unilateral por una de las partes, pero esta deberá 
Cabe señalar, por otra parte, que en los comentarios a las Reglas Modelo de Derecho Privado Europeo -Draft Common Frame of Reference (DCFR) - se expresa el principio general según el cual solo hay contrato cuando pueden determinarse con precisión el contenido y los términos del acuerdo entre las partes. Sin embargo, plantea las dificultades que surgen cuando aquellas dejan algunos términos abiertos, cuando acuerdan que celebrarán un contrato posteriormente y cuando han acordado un contrato marco. El DCFR tampoco menciona los contratos normativos, pero revela algunas de las cuestiones que surgen en el análisis de los contratos que son objeto del presente estudio.

En los mecanismos contractuales bajo examen suele generarse entonces un grupo de contratos vinculados entre sí, una coligación, "esto es, (...) una relación jurídica caracterizada por su complejidad e integrada por una multiplicidad de contratos que surgen a partir de un contrato principal, de modo que todos ellos comparten un objetivo y una causa común" (Soro Russell, 2014, p. 424), característica que es propia tanto de los contratos normativos como de los acuerdos marco.

En Colombia, diversos negocios han sido clasificados como contratos normativos o contratos marco en el derecho privado. En efecto, la doctrina y la jurisprudencia arbitral han calificado como tales los siguientes negocios, en la medida en que las partes establecen inicialmente unos parámetros generales para regir su relación - que planean como de larga duración- y luego concretan una serie de acuerdos sucesivos mediante los cuales desarrollan su relación económica:

(i) Distribución de bienes ${ }^{6}$,

(ii) Agencia comercial7

acreditar el importe en caso de impugnación. Si hubiere abuso en la fijación del precio, podrá demandarse judicialmente su revisión, considerando particularmente el uso, los precios del mercado, las expectativas legítimas de las partes, o podrá obtenerse el pago de perjuicios en caso de resolución del contrato.

6 Véase sobre el contrato de distribución como contrato marco, Domínguez García (1985, p. 485) Los Principios de Derecho Privado Europeo (Draft Common Frame of Reference) catalogan la distribución como contrato marco.

7 En un caso de agencia comercial se calificó este contrato como normativo y al respecto consideró el Tribunal: "El contrato normativo impone la celebración de esos contratos futuros y, por tanto, aquel participa de la función de los contratos preparatorios, generadores de obligaciones de contrahendo. Esos otros contratos futuros (...) son autónomos considerados en sí mismos, 
(iii) Fiducia mercantil ${ }^{8}, \mathrm{y}$

(iv) Concesión mercantil9 .

$\mathrm{Al}$ respecto, se ha señalado que "[e]l contrato marco, matriz o normativo previene la celebración y ejecución de otros contratos, que habrán de regirse por las pautas generales señaladas por aquel. El rasgo principal del contrato normativo consiste en determinar el contenido mínimo o pleno de otros contratos ulteriores, que se celebrarán entre las mismas partes o entre una de ellas y uno o varios terceros. Así las cosas, son contratos marco, entre otros, los de agencia, distribución y suministro" (Cámara de Comercio de Bogotá, 2009), pero debe anotarse que los contratos así celebrados tienen límites en el ámbito de la competencia en el mercado que debe salvaguardarse de las prácticas de abuso de posición dominante y de toda conducta que afecte negativamente a los consumidores y usuarios (Etcheverry, 2005, p. 140).

En los Principios Europeos antes mencionados, el contrato de distribución se categoriza como un contrato marco que provee el contexto para los contratos subsecuentes (contratos de aplicación). El primero establece una relación de colaboración entre las partes y suele definir solo los elementos básicos de los contratos futuros, mientras que los segundos normalmente son de corta duración y vinculan a las partes a obligaciones precisas; se concretan a través de órdenes que el distribuidor coloca al

pero frente al contrato de agencia o al de concesión son contratos auxiliares de ejecución complementaria, cuyo contenido está predeterminado en aquellos a plenitud o globalmente y son susceptibles de concreción, ajuste o alteración ulteriores. Por ello se habla de contratos marco, de contratos de apoyo, de contratos de aplicación, etc. (Pardolesi, 1979, pp. 445 y ss)". Laudo arbitral de Carlos Rincón Duque e Hijos Ltda. vs. Empresa Colombiana de Productos Veterinarios VECOL S. A. 19 de marzo de 1993. Cámara de Comercio de Bogotá.

8 "El contrato de fiducia celebrado sirve de régimen general para que el Fiduciario lleve a cabo en adelante múltiples operaciones de garantía con los beneficiarios de los certificados que expida. Se trata, entonces, de un marco reglado dentro del cual se desarrollan sucesivos negocios, lo que significa que es un medio para la conclusión de otros contratos, por lo que la doctrina moderna califica este tipo de relación mercantil como un contrato normativo, pues previene la celebración y ejecución de otros negocios, que habrán de regirse por las pautas generales señaladas en aquel". Laudo arbitral de Leasing Mundial vs. Fiduciaria FES, 26 de agosto de 1997, reiterado en los laudos de Monómeros Colombovenezolanos S. A. vs. Lloyds Trust (antes Fiduciaria Anglo S. A. - Fiduanglo), 20 de febrero de 2003 y de Vesna Zorka Mimica vs. Fiduagraria S. A., 28 de noviembre de 2001. Cámara de Comercio de Bogotá.

9 Laudo arbitral de Carlos Rincón Duque e Hijos Ltda. vs. Empresa Colombiana de Productos Veterinarios veCOL S. A. 19 de marzo de 1993. Cámara de Comercio de Bogotá (en este laudo, obiter dictum). 
proveedor (cantidades, precios, plazos, etc.). Uno de los efectos de esta interdependencia es que el incumplimiento de las obligaciones de los contratos de aplicación puede traer consecuencias sobre la relación de distribución ${ }^{10}$.

Por otra parte, algunos sectores económicos han desarrollado contratos marco para regular sus respectivas actividades. Ejemplo de lo anterior son los acuerdos de consorcio y de joint venture que plasman una serie de normas a las que deberán ajustarse los miembros de la asociación y que se complementan con convenios subsiguientes que se activan a medida que se desenvuelve la aventura común.

En el sector financiero es notable el desarrollo de los contratos marco para derivados, mediante los cuales se evidencia una creciente estandarización de los documentos que las partes utilizan para la negociación de estos productos especializados. Estas operaciones Over the Counter (OTC) se realizan en forma directa entre las partes y por fuera de las bolsas o mercados organizados.

De acuerdo con Fradique-Méndez (2008), en los años ochenta del siglo pasado se inició un proceso de uniformización de los documentos empleados en estas transacciones; la entidad encargada de desarrollar los contratos marco para estos negocios fue la International Swap Dealers Association (ISDA). Otras instituciones también optaron por este mecanismo de concertar contratos uniformes para sus respectivas operaciones. "Bajo este nuevo esquema -afirma el autor- las partes suscribían un 'contrato sombrilla' que regía todas las operaciones entre las partes, respecto de las cuales se anexaban unos documentos relativamente breves en los que se concretaban los términos de cada transacción" (p. 7). En Colombia se han desarrollado también algunos contratos marco para derivados, lo que demuestra el potencial que tiene dicho mecanismo contractual para agilizar y dar mayor certeza a las obligaciones y derechos de las partes en ciertas operaciones que se repiten en el mercado (Fradique-Méndez. 2008, pp. 25-27).

10 Véase sobre terminación del contrato por incumplimiento el Libro III, Capítulo 3, Sección 5, modificada por IV.E.- 2:304 de las Reglas, remedio que procede si el incumplimiento ha sido esencial. 
En síntesis, desde la perspectiva económica, los contratos marco y los contratos normativos responden a una necesidad de estandarizar los términos de los negocios que se celebran en diversos sectores de la economía y pueden originarse en las mismas partes contratantes y en organismos gremiales. Este mecanismo persigue la agilización de los procesos contractuales y a la vez la salvaguarda de la seguridad jurídica de las operaciones y los intereses de los intervinientes.

\section{Precisión necesaria: concepto, naturaleza jurídica y efectos de los contratos normativos y los contratos marco}

No obstante tener varios elementos en común, pero teniendo en cuenta la diversidad de posturas conceptuales que se han reseñado, en este aparte precisaremos lo que entendemos por una y otra categoría para destacar las diferencias jurídicas y operativas que existen entre el contrato marco y el normativo.

Por un lado, los acuerdos normativos, en sentido estricto, son aquellos mediante los cuales dos partes predisponen el contenido de futuros contratos que pueden, o no, celebrarse entre ellos o con terceros. De celebrarse los contratos de fondo, acogerán íntegramente o en forma parcial y de manera uniforme el reglamento adoptado de antemano. Aunque sus estipulaciones han sido preacordadas, los contratos de fondo que se celebren se entienden completos, eficaces y obligatorios por sí mismos si satisfacen los requisitos para su perfeccionamiento y validez.

El tradicional ejemplo de esta modalidad son las convenciones colectivas de trabajo que se incorporan en forma automática a los contratos laborales nuevos o en curso. Los contratos de franquicia también han sido catalogados como normativos en cuanto el franquiciante establece con el franquiciado las cláusulas que deberán contener los contratos que en lo sucesivo celebre este con sus clientes.

Así mismo, pueden considerarse contratos normativos los de servicios financieros en los que se establecen las estipulaciones de contratos futuros que pueden o no celebrarse con terceros. En este evento, se trataría de contratos normativos unilaterales al ser redactados por la entidad que ofrece masivamente el servicio a una clientela, como se explicará posteriormente. 
En cuanto al contrato marco, este recoge un acuerdo general sobre una materia, un corpus de cláusulas usuales como objeto, obligaciones de las partes, forma y plazos de entrega y de pago, duración, causales de terminación anticipada, confidencialidad, etc. No regula intereses concretos y actuales, sino que pretende disciplinar futuras y eventuales relaciones jurídicas (Bernal, 2018, p. 2). Este acuerdo se activa cuando, en vigencia del mismo, se suscriben contratos de aplicación. En principio, las partes no están obligadas a celebrar con posterioridad los "acuerdos de ejecución" o de hacerlo en determinadas épocas o respecto de ciertos montos. Si lo hacen - porque surge la oportunidad propicia-, desarrollarán el negocio generalmente a través de órdenes de bienes, trabajos o servicios u otros mecanismos análogos que detallan específicamente lo que habrá de cumplirse y regirán para dicha ejecución las cláusulas generales del contrato marco.

El contrato inicial y sus correspondientes contratos de aplicación se complementan mutuamente e integran en un acto plural, complejo pero unitario, por su función económica. A esta acepción se refiere el Artículo 1109 del Código Civil francés.

Ambas categorías - contratos marco y normativos - comparten una estructura dual: existe un contrato principal o regulador y se contempla la celebración de otros negocios futuros, como lo señala Soro Russell (2014, p.137), pero en los primeros hay un desarrollo a través de contratos de aplicación, mientras que en los segundos se deja listo un clausulado que regirá en los negocios que se celebren con posterioridad entre las mismas partes, o entre una de ellas y terceros. Aunque la doctrina suele asimilar los dos conceptos, el tratadista mencionado señala agudamente que en los contratos marco hay un contenido inmediatamente vinculante para las partes, lo que se ha pasado por alto en las definiciones de contrato normativo (Soro Russell, 2014, p. 163).

\section{La función económica}

La génesis de los contratos normativos y los contratos marco se encuentra, indudablemente, en la necesidad de organizar los procedimientos contractuales de manera más eficiente y en la conveniencia de 
que los empresarios cuenten con una forma de contratación ágil en el mercado que facilite la estandarización, con ahorro de tiempo y de costos de transacción.

Sobre el contrato normativo se ha planteado que "[e]ste singular vínculo jurídico, más que posibilitar un intercambio puntual de bienes y servicios, parece perseguir la instauración o consolidación de una relación de cooperación fluida, estable y duradera entre las partes, con el fin de simplificar la celebración de los negocios que en un futuro puedan llevarse a cabo tanto entre ellas como con terceros" (Soro Russell, 2014, pp. 25-26). Esta peculiar forma de contratar se prefiere en situaciones normalmente complejas, de bastante estabilidad y de larga duración (De la Cuesta Sáenz, 2013, p. 210; Soro Russell, 2014, pp. 282-283), función económica que es así mismo predicable de los contratos marco.

$\mathrm{Al}$ respecto ha señalado la jurisprudencia arbitral colombiana que el contrato normativo - que como ya se anotó ha asimilado a los contratos marco-

[e]s el producto de las necesidades empíricas de los empresarios que ven en esta forma de contratación ciertas ventajas para relaciones negociales duraderas entre las mismas partes. La adopción de dicha tipología es común en contratos de distribución, joint ventures y otros acuerdos de colaboración porque permiten establecer un esquema general que permanece estable pero introduce un factor de flexibilidad a través de los contratos de aplicación que pueden celebrarse de tiempo en tiempo, mientras el contrato marco se encuentre vigente (Cámara de Comercio de Bogotá, 2015).

Tanto los contratos normativos como los marco son mecanismos de contratación en el mundo empresarial contemporáneo que no distingue entre culturas jurídicas, puesto que se emplea en operaciones de pequeña, mediana y gran escala en economías de mercado pertenecientes al derecho continental -como se evidencia en las precisiones doctrinales anteriores- y también en países de tradición legal anglosajona. En estos se emplean con frecuencia los denominados framework agreements, conocidos en algunos ámbitos como master agreements o umbrella agreements, que se aproximan al concepto de contratos marco. 
Los acuerdos marco tienen los rasgos ya esbozados: unas directrices pactadas ab initio que gobernarán la relación de negocios y múltiples acuerdos posteriores que desarrollarán en concreto el intercambio entre las partes, respetando el marco general: son los ya referidos como contratos de aplicación o de ejecución. La combinación de los dos convenios ha resultado útil en diversos sectores económicos que requieren términos más o menos uniformes en la respectiva industria y son ampliamente utilizados en diversas actividades como el suministro de bienes y servicios (procurement) (Chartered Institute of Procurement and Supply, 2016) en la construcción y en la industria petrolera ${ }^{11}$, entre otras.

\section{Mecanismos afines}

Es mucho lo que se ha escrito sobre la formación de los contratos y sobre las vicisitudes que conlleva el proceso que inicia en las conversaciones preliminares entre personas interesadas en un negocio y llega hasta la obtención de un contrato celebrado, perfeccionado y plenamente eficaz. En el derecho actual, ese interrogante supera la tradicional y simplista combinación de la oferta y la aceptación. Sobre estos problemas, la catedrática María Ángeles Parra destaca como elemento clave para determinar si el contrato quedó perfeccionado, la valoración de si el acuerdo es suficiente y de si hay intención de las partes de quedar vinculadas (Parra Lucán, 2014, p. 80). Sin embargo, no son infrecuentes las situaciones intermedias entre contrato definitivo y falta de contrato (Parra Lucán, 2014, p. 87), lo que evidencia la multiplicidad de posibilidades y dificultades que existen en el iter contractus: es un camino cada vez más complejo, a veces largo y lleno de vías secundarias, desvíos e incertidumbres.

En este escenario es oportuno examinar la particular naturaleza de los contratos normativos y de los contratos marco. La doctrina, en un

11 En la industria petrolera, el Master Service Agreement para la adquisición de bienes y servicios contiene las cláusulas contractuales usuales (contrato-marco), pero se activan mediante órdenes de trabajo u órdenes de servicio, conocidas como llamados o call-offs que son "minicontratos" individuales que se producen de tiempo en tiempo. A título ilustrativo, véase un modelo de este contrato en: http://www.eogresources.com/operations/business/Domestic_Master_Service_Agreement.pdf (recuperado el $1^{\circ}$ de junio de 2016). 
intento por superar las dificultades semánticas y conceptuales, se ha ocupado de caracterizarlos frente a otros fenómenos convencionales con los que guardan alguna semejanza, en particular el hecho de que todos acontecen en la fase de diseño y formación de los contratos, etapa en la que las partes pueden alcanzar entendimientos y puntos de convergencia con distintos grados de obligatoriedad.

Los acuerdos previos que son preparatorios y conducen a la celebración de un contrato definitivo y principal de contenido predeterminado son genéricamente precontratos (Rengifo, 2016, pp. 319-320). Entre ellos, Rengifo identifica tres categorías: los contratos de negociación, los normativos y los preliminares. Su mayor o menor fuerza vinculante depende de si generan en forma directa la obligación de concluir futuros negocios o de si las obligaciones específicas solo nacen por la existencia sucesiva de otros acuerdos que incorporen el reglamento preestablecido o por la efectiva celebración de contratos de aplicación, como ocurre con los contratos normativos y con los contratos marco respectivamente, lo que llevaría a plantear que el efecto de estos sobre el nacimiento de derechos y obligaciones es indirecto o mediato.

Para este propósito, se ha distinguido el contrato preliminar del contrato preparatorio, aunque debe advertirse que en este aspecto tampoco hay consenso doctrinal en cuanto a la terminología empleada. Ambos negocios contemplan la celebración de acuerdos futuros, pero el acuerdo preliminar no obliga a las partes a concluirlos, como es el caso del contrato marco y del normativo mientras que, en virtud del contrato preparatorio, las partes sí están vinculadas por una obligación de hacer que consiste en concluir futuros contratos, como sucede con la promesa ${ }^{12}$ (D'Arcangelo, 2008, p. 64; De la Cuesta Sánez, 2013, p. 210).

12 “(...) lo que caracteriza al llamado contrato normativo frente a los contratos preliminares, es que aquel no genera obligación de contratar en concreto, sino mera obligación, para el caso de que se contrate, de hacerlo en cierto modo o dentro de cierto marco". En sentido contrario opina Díez Picazo (1996, p. 363), para quien en los contratos preliminares nace la obligación de concluir el contrato definitivo. Gregorini (2009, p.382) considera que los contratos preparatorios son una especie de contratos previos que, si bien contemplan una eventual contratación futura, a diferencia de los contratos preliminares no obligan a contratar sino que se limitan a establecer las bases para hacerlo. Sin embargo, para Gete-Alonso (1997, p. 569), el contrato normativo es definitivo: "Mientras que en el precontrato existe ya un contrato que, en un momento posterior se puede poner en vigencia por las partes, el contrato normativo es, en sí, un contrato ya definitivo cuya característica radica en su contenido (las reglas o normas a las que se someten las partes); 
Sobre el contrato normativo y el preliminar, señala Balestieri (2012) con apoyo en la doctrina, que son dos especies que tienen en común "que una actividad contractual sea a su vez objeto de otra actividad contractual previa"; la diferencia radica en que esta última puede dirigirse a asegurar la conclusión de futuros contratos (caso de los contratos preliminares) o a insertar en los mismos determinadas cláusulas acordadas previamente (contratos normativos). Los contratos que se celebran posteriormente los denomina "contratos actuativos" (p. 1418).

En línea con los planteamientos de Betti, estima Balestieri que los contratos normativos son acuerdos de formación progresiva que solo se realizarán cuando se estipule el contrato particular. "La función del contrato objeto de estudio, consiste en asegurar a las partes que logren un acuerdo sobre el contenido de cláusulas particularmente complejas, destinadas a realizarse luego de la suscripción de una serie de contratos particulares", creándose entre ambos una relación funcional (Balestieri, 2012, p. 1418). A diferencia de Messineo, que abogó por la tesis del acuerdo y no del contrato en sentido estricto, en esta materia Balestieri afirma la naturaleza contractual del contrato normativo.

Para precisar su naturaleza jurídica, revisaremos distintas figuras afines a los contratos normativos y a los contratos marco.

(i) Promesa de contrato. En la promesa, que es un contrato preparatorio y provisional, las partes acuerdan que celebrarán un contrato futuro que determinan, plenamente, en sus elementos esenciales. En virtud de la promesa nace para ambas la obligación de hacer que consiste en perfeccionar el contrato definitivo en un momento futuro que también se fija con precisión a través de un plazo o una condición (Código Civil, Artículo 1611; Código de Comercio, Artículo 861). La celebración del contrato prometido agota el objeto del contrato de promesa que queda, por ende, extinguido. Por ser un contrato bilateral, el incumplimiento de la promesa concede al acreedor la opción de pedir la ejecución forzosa de la obligación o la resolución del contrato de promesa, con indemnización de perjuicios.

de él no se deriva la obligación de contratar en el futuro, sino solo la de que, en el caso de que así suceda, se respeten las reglas acordadas". 
(ii) Opción. Es un contrato preparatorio en que las partes visualizan la eventual conclusión de un negocio jurídico futuro y definitivo: el concedente de la opción otorga al beneficiario de esta, con exclusividad y durante un plazo fijado, el derecho de celebrar el contrato futuro -que se identifica plenamente- conservando el beneficiario la libertad para decidir si lo celebra o no ${ }^{13}$.

(iii) Pacto de preferencia. Las partes acuerdan que, si una de ellas decide celebrar determinado contrato -a lo que no queda obligado- deberá hacerlo con el beneficiario (Código de Comercio, Artículo 862). Este pacto tiene en común con el contrato normativo la posibilidad, mas no la obligación, de celebrar un contrato futuro entre las partes que lo acuerdan pero, en aquel, la decisión de contratar proviene en forma unilateral de quien lo estipula y debe concluir el contrato con el beneficiario de la preferencia, al paso que en el contrato normativo puede afirmarse que, en general, la decisión de celebrar el contrato de fondo la toman de consuno las dos partes, o una de estas con los terceros a los que se dirige.

(iv) Condiciones generales y especiales de contratación. Las primeras son verdaderos reglamentos contractuales que fijan de manera unilateral el contenido de un negocio, por iniciativa del predisponente, con carácter uniforme para todos aquellos que deseen concluir ese determinado contrato. Las condiciones especiales contienen datos y estipulaciones que individualizan la relación particular e introducen, en algunos eventos, variaciones a las condiciones generales para el caso concreto. En los contratos marco o normativos, en cambio, las reglas que se fijan inicialmente para regir futuros contratos, por lo general se establecen de común acuerdo entre las partes (Rengifo, 2016, p. 378). Además, las condiciones especiales no pueden asimilarse a los contratos de fondo subsecuentes en materia del contrato marco, puesto que aquellos son contratos en sí mismos -aunque coligados con aquel- a diferencia de las condiciones especiales que forman parte del acuerdo negocial unitario.

13 La Ley 51 de 1918, en su Artículo 23 define el contrato de opción: "La opción impone al que la concede la obligación de cumplir su compromiso. Si la opción no estuviere sometida a un término o a una condición, será ineficaz. La condición se tendrá por fallida si tarda más de un año en cumplirse. Las partes pueden ampliar o restringir este plazo". 
(v) Contratos por adhesión. En estos, el destinatario de una oferta contractual, generalmente de carácter uniforme y masivo, acepta el contenido previamente determinado por el oferente sin que haya un proceso previo de negociación ni la posibilidad de discutir sus términos o de formular contraofertas. En principio, el contrato normativo y los acuerdos que lo desarrollan son producto de la libre negociación de las personas que intervienen en el negocio después de un período de discusiones, ofertas y contraofertas, de manera que los contratos nacen del acuerdo de las voluntades de los partícipes. Sin embargo, cabría la posibilidad de que los contratos marco o normativos resulten de la imposición de condiciones generales a las que adhiere una de las partes.

En algunos sectores de la economía los formularios tipo predispuestos por el profesional que prestará un servicio masivo son materia de un control de legalidad por parte de la autoridad de supervisión, por ejemplo, los contratos bancarios, de fiducia y de seguros, cuyos términos en Colombia se someten a aprobación por la Superintendencia Financiera, y que se incorporan en los respectivos contratos que se celebrarán con la clientela ${ }^{14}$.

(vi) Contratos-tipo. El contrato tipo es un modelo elaborado por personas, asociaciones o colectividades distintas a los sujetos que van a suscribirlo con contenido idéntico en sucesivas operaciones que se celebrarán entre el contratante que adopta el contrato tipo y terceros (D'Arcangelo, 2008, pp. 65-66). El contrato normativo y sus contratos particulares de fondo pueden ser celebrados por las mismas partes o por alguna de ellas y terceros, según se mencionó anteriormente. En los contratos marco, en cambio, las mismas partes son las que celebran el acuerdo inicial y los subsiguientes contratos de aplicación. La naturaleza jurídica del contrato normativo y del contrato marco se encuentra íntimamente ligada a lo tratado anteriormente sobre su identidad propia, frente a figuras negociales afines.

14 Véanse, por ejemplo, el numeral 4 del Artículo 146 del Estatuto Orgánico del Sistema Financiero y el Artículo 3 del Capítulo Primero del Título V de la Circular Externa 046 de 2008 de la Superintendencia Financiera. 
Los contratos normativos se han entendido como pactum de modo contrahendi, es decir, que las partes no se obligan a celebrar un contrato futuro sino a contratar de cierto modo si deciden hacerlo (Rezzonico, 1987, p. 234). Además, como ya se mencionó, a diferencia de los contratos preparatorios, el contrato normativo subsiste y permanece apto para regir la conclusión de cualquier otro contrato futuro que caiga en el ámbito de su regulación (Farina, 2005, p. 108). Ello difiere de la estructura de los contratos marco que requieren de un esquema general de obligaciones y de unos acuerdos específicos que desarrollan gradualmente el negocio.

Para comprender mejor el fenómeno que se presenta en los dos mecanismos que se examinan, resultan igualmente provechosas las consideraciones de Betti (2000) en torno a la clasificación del negocio jurídico como simple o complejo, útil para establecer -cuando hay una pluralidad de actos o manifestaciones de voluntad- si hay una unidad o si hay nexos de interdependencia entre negocios que se forman sucesivamente (p. 250).

Afirma el autor:

El problema enunciado radica en ver cuándo y por qué se deba reconocer un negocio único con pluralidad de declaraciones y cuándo en cambio, nos encontramos ante una multiplicidad de negocios, unidos en un supuesto de hecho complejo, por nexos que no excluyen el valor autónomo de cada uno (...). Dada una pluralidad de declaraciones conexas ha de distinguirse si a cada una de ellas se acompañan, como efectos propios e independientes, los efectos jurídicos correspondientes a su finalidad, o bien si tales efectos solo se enlazan al complejo de las declaraciones conjuntas. En la primera hipótesis se tienen varios negocios coligados, en la segunda, un negocio unitario que consta de varias declaraciones (Betti, 2000, pp. 251-253).

Señala, además, que hay concurso de negocios cuando por la relación que hay entre ellos cooperan al mismo resultado económico-social. Aunque cada uno de los negocios concurrentes o en vínculo de continuidad produce efectos jurídicos conforme a su destino, los efectos son tales que constituyen una unidad funcional, de suerte que el nexo es esencialmente teleológico. Dicho nexo puede tener características ya sea de subordinación a una operación compleja o de secuencia. En este sentido, se ha 
considerado que el "contrato normativo" pertenece al amplio fenómeno de la formación progresiva del contrato (Civitelli, 2015), aseveración que consideramos aplicable así mismo a los contratos marco.

Si bien Betti en su análisis no hace referencia explícita a los contratos normativos, es evidente que ellos, en sí mismos, no tienen la fuerza vinculante inmediata de un contrato en sentido clásico en la medida en que no generan derechos ni obligaciones entre las partes: ni siquiera las obliga a concluir contratos futuros y mucho menos da nacimiento a las prestaciones propias de los contratos de fondo. Para ello se requiere la efectiva conclusión de estos últimos que son jurídicamente autónomos - aunque unidos por una misma finalidad económica- y, como dice el tratadista, cada uno tiene su propia fisonomía y eficacia y se proyecta a un mismo fin. Los acuerdos marco tampoco obligan a las partes a concluir un número prefijado de contratos de aplicación.

Las anteriores anotaciones son, a nuestro juicio, pertinentes para comprender la verdadera naturaleza de los contratos objeto de examen que no obedecen a las categorías tradicionales del derecho civil, sino que son producto de la autonomía de la voluntad que precisa adaptarse a los requerimientos de la economía moderna.

Así, quienes celebran un contrato normativo anticipan la necesidad de contar con unas reglas contractuales definidas y uniformes que se dejan a punto, a la espera de las oportunidades futuras de concluir negocios por los que se desarrollen y se lleven a la práctica las normas así concebidas. El contrato normativo queda en una especie de stand-by y, aunque eficaz, carece, en sí mismo, de la especificidad necesaria para traer a la vida una relación dinámica y fluida, susceptible de ejecución forzosa por incumplimiento (enforceablity), sin que pueda tampoco afirmarse que se trata de un acuerdo inocuo, sin ningún efecto vinculante (los non-binding agreements del common law), en la medida en que será de obligatoria observancia en los negocios subsecuentes que sobre la materia celebren las partes. En los contratos marco, las partes convienen el clausulado general que prevé la suscripción futura de acuerdos específicos que desarrollen su operación comercial a través de pedidos, órdenes de trabajo o servicios con datos puntuales que concretan las respectivas obligaciones.

Es evidente que el contrato normativo y el contrato marco requieren la conclusión sucesiva de uno o más acuerdos que encuadren en la 
reglamentación preacordada y los contratos así articulados en distintas etapas se convierten en una unidad negocial, empleando la terminología de Betti: hay un negocio matriz y uno o más negocios subsecuentes, cada uno con sus propios elementos, pero la finalidad económica que comparten impide verlos como relaciones aisladas.

\section{Preguntas de reflexión y conclusiones}

A título de síntesis y como reflexiones finales cabe preguntarse, en primer término, en vista de la función, la naturaleza jurídica y la forma en que operan los contratos normativos y los contratos marco, ¿son estos verdaderos contratos y tienen fuerza vinculante?

Para abordar este interrogante parece razonable concluir con la doctrina contemporánea de que los instrumentos estudiados son verdaderos contratos que pueden encuadrarse en la amplia concepción de este fenómeno jurídico, en la que caben diversas manifestaciones y modalidades. Se trata, como lo expresa el Código francés, de un acuerdo de voluntades para generar efectos jurídicos. Estos pueden consistir en la creación de pautas y reglas convencionales que se incorporarán a una serie de contratos futuros, si estos llegan a concluirse (normativos), o las pautas generales que se desarrollarán mediante acuerdos específicos (marco).

En segundo lugar podría pensarse que, en realidad, tanto el contrato normativo como el contrato marco son "contratos incompletos" en la medida en que carecen, por sí mismos, de la fuerza vinculante necesaria para regular una relación patrimonial específica y porque sin los contratos de fondo o de aplicación son figuras jurídicas en el limbo, a las que le faltan otras declaraciones de voluntad para ser eficaces, aplicables y ejecutables.

Según la doctrina,

el contrato puede entenderse celebrado cuando las partes hayan logrado el acuerdo sobre el llamado 'contenido mínimo' del contrato que, además de los requisitos esenciales, podría también comprender elementos secundarios, con tal que las partes hayan convenido de manera conjunta atribuirles un carácter de esencialidad (Farina, 2015, p. 121). 
El contrato es incompleto, entonces, cuando, al ser válido, carece de los elementos mínimos necesarios para su aplicación y en razón de ello presenta lagunas o gaps que deben llenarse conforme a las reglas correspondientes. Según Farina, en los ordenamientos del common law la sola ausencia de disciplina de un aspecto de la relación provoca la manifestación de un gap, mientras que en los ordenamientos de civil law el intérprete está llamado a ejecutar un segundo orden de controles para llenar los vacíos contractuales.

El contenido negocial con lagunas sufre de hecho una integración automática, que opera desde la formación del contrato y ope legis: solo en ausencia de una disposición legal, el negocio -válido, por supuesto- operará en el mundo del derecho, incluso sin especificar de forma rigurosa todas las obligaciones de las partes (Farina, 2015, pp. 122-128).

Así las cosas, no podría esgrimirse que el esquema contractual complejo integrado por el acuerdo normativo o el contrato marco con sus respectivos contratos de ejecución o aplicación adolezca de falta de completitud, en cuanto no hay un problema de lagunas contractuales sino que existe la interacción de dos acuerdos que integran una unidad negocial.

Los principios UNIDROIT para la contratación internacional no regulan los contratos normativos ni los contratos marco. Sus artículos 2.1.13 y 2.1.14 hacen mención de supuestos que resultan interesantes en una reflexión sobre el carácter "completo" de los contratos y sobre si estos se entienden perfeccionados cuando faltan algunos elementos o si se dejan términos abiertos.

El Artículo 2.1.13 dispone:

Cuando en el curso de las negociaciones una de las partes insiste en que el contrato no se entenderá perfeccionado hasta lograr un acuerdo sobre asuntos específicos o una forma en particular, el contrato no se considerará perfeccionado mientras no se llegue a ese acuerdo.

En el comentario oficial a la primera parte de esta norma, se distingue entre los elementos esenciales y los "aspectos de menor importancia" en el contrato; estos pueden ser integrados posteriormente, a menos que una de las partes insista en que el acuerdo no se entiende concluido sin 
esos aspectos accidentales, por ejemplo, cuál de las partes debe sufragar los costos de publicidad un en contrato de distribución.

Por su parte, el Artículo 2.1.14 prevé el supuesto del contrato con términos abiertos:

(1) Si las partes han tenido el propósito de celebrar un contrato, el hecho de que intencionalmente hayan dejado algún término sujeto a ulteriores negociaciones o a su determinación por un tercero no impedirá el perfeccionamiento del contrato. (2) La existencia del contrato no se verá afectada por el hecho de que con posterioridad: (a) las partes no se pongan de acuerdo acerca de dicho término; o (b) el tercero no lo determine, siempre y cuando haya algún modo razonable para determinarlo, teniendo en cuenta las circunstancias y la común intención de las partes.

En los eventos mencionados se hace referencia a la intención de perfeccionar un contrato, mas no al mecanismo reflexivamente adoptado de preacordar unas estipulaciones que regirán contratos futuros - contrato normativo- o que deberán desarrollarse con contratos de ejecución -contratos marco-.

Teniendo en cuenta las características especiales y la función del contrato normativo y del contrato marco, tampoco pueden, a nuestro juicio, categorizarse como actos jurídicos cuyas obligaciones están sometidas a una condición suspensiva que consiste en la celebración de los contratos futuros, de suerte que aquellos no nacerían si los contratos futuros no llegaran a perfeccionarse. Como se ha mencionado, en ambos casos los dos acuerdos (inicial y posterior) tienen una relación teleológica, forman parte de un esquema complejo que se configura en la génesis de una operación económica, pero no pierden su identidad como negocios jurídicos individuales.

Una tercera pregunta es si debe presuponerse la igualdad de las partes que convienen un acuerdo normativo o un contrato marco, porque las posturas doctrinales que se han reseñado mencionan que los intervinientes, de común acuerdo, establecen las reglas que habrán de cobijar los futuros contratos - si ellos en efecto se celebran-o la manera de desarrollar puntualmente la operación correspondiente. Al respecto conviene señalar que, como regla general, este tipo de acuerdos son propicios entre empresarios profesionales que conocen el mercado y que están en posibilidad de 
establecer reglas contractuales mutuamente satisfactorias, en una relación equilibrada de las catalogadas como business to business (BtoB).

Sin embargo, no se descarta que en muchas situaciones haya asimetría de información y de poder económico que sitúe a uno de los contratantes en posición de dominio que le permita, en forma unilateral, predisponer el contenido del acuerdo normativo o del acuerdo marco con los elementos que los caracterizan.

Así las cosas, no es exótico el evento en el que una persona, en forma unilateral, predispone e impone los términos de un contrato normativo o de un contrato marco a otra, que los acepta o los rechaza, para entrar en un terreno semejante al de las condiciones generales, de la adhesión y del peligro de abuso de posición dominante en el mercado o en el contrato, evento en el que deben aplicarse con cautela los correctivos que demande la justicia y la equidad en el caso concreto.

Otro aspecto - cuarto interrogante- tiene que ver con la extensión de los contratos normativos a terceros que no han participado en su confección. La doctrina italiana señala que los contratos normativos pueden ser internos o externos. En los primeros, las partes son las mismas que intervienen en los contratos subsecuentes, mientras que los externos reglamentan cláusulas de los contratos sucesivos que podrán celebrarse por una de las partes y terceros, como ocurre en los contratos de franquicia (Roppo, citado en Balestieri, 2012, p. 1423).

En este campo, la pregunta fundamental tiene que ver con la obligatoriedad para los terceros de las cláusulas acordadas entre las partes del contrato normativo en presencia del principio de la relatividad, según el cual a ningún tercero se extienden los efectos del acto por no haber prestado su consentimiento. Hueck (1923) considera que las estipulaciones del contrato normativo solo serán aplicables a las relaciones con un tercero si aquellas se incluyen específicamente en el contrato particular (p. 102).

De otro lado, en los contratos normativos externos, si la parte que tiene a su cargo la celebración de ulteriores acuerdos con terceros viola lo que fue previamente acordado en el contrato normativo y conviene un contenido distinto en el contrato particular, dicha parte se expone a responsabilidad por incumplimiento del contrato normativo, pero ello no incide en la eficacia del contrato celebrado con el tercero (Balestieri, 2012, p. 1424). 
Como quinto y último cuestionamiento, surge lo relativo al incumplimiento del acuerdo normativo y del contrato marco en dos escenarios.

(i) Si al llegar el momento de suscribir el contrato previsto en el acuerdo normativo, una de las partes se aparta de lo convenido y frustra la conclusión del contrato particular, ¿hay incumplimiento? Dicho comportamiento puede considerarse como infracción al acuerdo normativo, una falta de corrección que atenta contra la buena fe y la confianza legítima y, por ende, como incumplimiento, sobre todo si se hace en forma arbitraria y sin suficiente motivación que justifique una renegociación de sus términos (Citivelli, 2015).

(ii) En los contratos marco, si la parte que tiene la iniciativa para activar los contratos de aplicación, hacer pedidos, etc., no lo hace y en forma indefinida mantiene una conducta pasiva, iincumple el contrato? Como se ha mencionado con insistencia, las partes no tienen la obligación de celebrar contratos futuros pero, ¿podría pensarse que el acuerdo inicial crea una expectativa legítima de que habrá futuros negocios que, al no concretarse, lesione el interés negativo de confianza de la otra parte? ¿Y hay alguna consecuencia jurídica si una de las partes abandona su interés en celebrar los contratos de aplicación? ¿Decae el contrato marco por inacción de una o ambas partes? Aquí conviene anotar que en el contrato marco, aunque no haya obligación de concluir los contratos futuros de aplicación, como en todo contrato rige el principio supremo de la buena fe y del mismo surgen deberes secundarios de conducta (información, lealtad, corrección, cooperación) que imponen en las partes comportamientos más allá de lo que exprese el contrato mismo. Así las cosas, si la negativa a concluir negocios de aplicación tiene motivos legítimos, no habrá reproche a la conducta de la parte en cuestión. Pero si la abstención tiene como móvil crear situaciones ambiguas para restringir la libertad de empresa o la libre competencia imponiendo cláusulas de exclusividad, o creando inhabilidades para celebrar contratos con terceros, o cortinas de humo para negociar paralela y deslealmente con otros proveedores causando perjuicios a la otra parte, el juez, sin duda, encontrará fundamento para condenar conductas reprochables que agravien los intereses legítimos de los contratantes. 
Finalmente, consideramos procedente que, en un esfuerzo encaminado a modernizar el régimen colombiano de la formación de los contratos, además de revisar a fondo la normativa sobre oferta y aceptación, hay que reglamentar en forma sistemática los acuerdos preparatorios que hoy carecen de una estructura clara y armónica, para que nuestro ordenamiento reconozca mecanismos que hoy en día utilizan los empresarios en el mercado para la celebración de sus negocios, estableciendo unas pautas mínimas que orienten el proceso de gestación de los negocios, en particular en materia de contratos normativos y contratos marco.

\section{Referencias}

Balestieri, M. (2012). Il contratti preparatori: il contrati normativo. En P. Fava (ed.). Il contrato (pp. 1417-1427). Milán: Guiffré.

Bernal, M. (2018). Reflexiones sobre los contratos marco. Vniversitas, 67(136), 1-19. Betti, E. (2000). Teoría general del negocio jurídico. Granada: Comares.

Citivelli, S. (2015). Nozione di contratti normative. Recuperado de https://www. tesionline.it/v2/appunto-sub.jsp? $\mathrm{p}=110 \mathrm{Gid}=440$

Chatered Institute of Procurement and Supply. (2016). Master Service Agreement.

Recuperado de https://www.cips.org/Documents/Resourses/Knowledge\%20 Summary/Framework\%20Arrangements.pdf

De la Cuesta Sáenz, J. M. (2013). Contratos normativos. En Contratación contemporánea (pp. 208-227). Valladolid: Universidad de Valladolid.

Díez-Picazo, L. (1996). La teoría del contrato. En Fundamentos del derecho civil patrimonial. Madrid: Civitas.

D'Arcangelo, F. (2008). Il contratto normativo. La rassegne. Obbligationie contratti, pp. 62-66. Roma: Wolters Kluwer Italia SRL.

Domínguez García, M. A. (1985). Los contratos de distribución. Propuesta de construcción unitaria. Extremadura: Facultad de Derecho de la Universidad Extremadura.

Escobar Sanín, G. (1994). Negocios civiles y comerciales. Vol. II. El contrato. Medellín: Editorial Diké.

Etcheverry, R. A. (2005). Obligaciones y contratos comerciales. Buenos Aires: Astrea. Farina. J. M. (2005). Contratos comerciales modernos. Buenos Aires: Astrea.

Farina, M. (2015). Integración del contrato "incompleto" en el ordenamiento italiano. Revista de Derecho Privado Universidad Externado de Colombia (29), 113-139. 
Fradique-Méndez, C. (2008). Aspectos legales de los contratos marco para derivados. Revista de Derecho Privado de la Universidad de los Andes (39), 1-39.

Gete-Alonso, M. del C., (1996). La formación del contrato. En L. P. Ferriol, M. del C. Gete-Alonso, J. G. Rodríguez y J. J. H. Sánchez (eds.). Manual de derecho civil: derecho de obligaciones. Responsabilidad civil. Teoría general de contrato (pp. 549-570). Vol 2. Madrid: Marcial Pons.

Gregorini Clusellas, E. (2009). Derecho de los contratos I. Buenos Aires: Hammurabi. Hinestrosa, F. (2015). Tratado de las obligaciones Tomo II, Vol. 1 Bogotá: Universidad Externado.

Hueck, A. (1923). Contratos normativos. En Anuario de Ihering para la dogmática del derecho civil (pp. 33-118). Jena: Editorial Gustav Fischer.

Lorenzetti, R. L. (2004). Tratado de los contratos. Santa Fe: Rubinzal Culzoni Editores. Messineo, F. (1948). Doctrina general del contrato I. Buenos Aires: Ediciones jurídicas Europa-América.

Pardolesi, R. (1979). I contratti di distribuzione. Napoles: Jovene.

Parra Lucán, M. A. (2014). La formación del contrato como proceso. En AA.VV. Negociación y perfección de los contratos (pp. 57-135). Pamplona: Thomson Reuters-Aranzadi,

Rengifo, M. (2016). La formación del contrato. Bogotá: Temis-Uniandes.

Rezzonico, J. C. (1987). Contratos con cláusulas predispuestas. Buenos Aires: Astrea.

Soro Russell, O. (2014). Los contratos como fuentes de normas: contratos marco, contratos normativos y contratos de colaboración. Madrid: Reus.

\section{Referencias de jurisprudencia arbitral}

Cámara de Comercio de Bogotá. (19 de marzo de 1993). Laudo arbitral de Carlos Rincón Duque e Hijos Ltda. vs. Empresa Colombiana de Productos Veterinarios VECOL S. A.

Cámara de Comercio de Bogotá. (26 de agosto de 1997). Laudo arbitral de Leasing Mundial vs. Fiduciaria FES.

Cámara de Comercio de Bogotá. (20 de febrero de 2003). Reiterado en los laudos de Monómeros Colombo-Venezolanos S. A. vs. Lloyds Trust (antes Fiducidiaria Anglo S. A.)

Cámara de Comercio de Bogotá. (28 de noviembre de 2001). Vesna Zorka Mimica vs. Fiduagraria S. A.

Cámara de Comercio de Bogotá. (14 de septiembre de 2015). Laudo arbitral de Obras Civiles y Construcciones para la Industria Petrolera S. A. vs. Petrominerales Colombia Ltda. Sucursal Colombia.

Cámara de Comercio de Bogotá. (8 de febrero de 2016). Laudo arbitral de A. S. Ingeniería Puntual S. A. S. vs. Perenco Oil \& Gas Colombia Limited. 